\title{
A Morphologic And Morphometric Study Of The Foramen Lacerum In Adult Human Skulls: An Osteological Study In Upper Egypt
}

\author{
Abeer Fareed Abd EL Naeem \\ lecturer.of human Anatomy \& Embryology department. Sohag University.
}

\begin{abstract}
Background:Foramen lacerumis one of the foramen at the base of skull lies between the occipital bone and the petrosal portion of the temporal boneand sphenoid boneIt allows passage ofinternal carotid artery , ascending pharyngeal artery and emissary veins from the cavernous sinus.Variability in anatomical aspect ofthis foramen has been studied by many workers in different part of the world.

Aims \& Objective:To study the variability in shape and size of foramenlacerum.

Materials andMethods: Present study has been designed to study on 100 skulls $(100 \times 2=200$ foramen $)$.

Result:The mean AP.diameter on right was $10.89 \mathrm{~mm}$,and on left it was $10.88 \mathrm{~mm}$. The mean transverse diameter on right was $6.85 \mathrm{~mm}$, on the left $6.59 \mathrm{~mm}$.

Conclusion:The clinical significance of foramen lacerumis important during surgeries. Therefore, the dimensions of foramenlacerumis much necessary.

Key words:Foramen lacerum,internal carotid artery,cavernous sinus.
\end{abstract}

\section{INTRODUCTION}

Foramen lacerum is a hole that is found at the base of the skull, with a characteristic triangular shape. These are the elements that surround the foramen lacerum and practically contribute to its formation: sphenoid bone (anterior border), petrous temporal bone (more exactly, its apex) and the occipital bone (specifically, the basilar part) (Standring, 2008). It is known that foramen lacerum is located anteriorly and medially from the carotid canal. The hole is covered by cartilage (connective tissue) in the postnatal period(Drake et al., 2015).

It measures approximately $9 \mathrm{~mm}$ in length and $7 \mathrm{~mm}$ in breadth. The foramen lacerum is filled with connective tissue and transmits the small meningeal branches of the ascending pharyngeal artery and emissary veins from the cavernous sinus. The internal carotid artery passes along its superior surface but does not traverse it (Lang, 2001).
In the foramen lacerum the greater petrosal nerve joins with the deep petrosal nerve to form the nerve of the pterygoid canal. The deep petrosal nerve carries sympathetic and the greater petrosal nerve carries parasympathetic fibers

ofthe autonomic

nervous

system to blood vessels, mucous membranes, salivary glands, and lacrimal glands (Snell, 2012).

Some emissary veins pass through the foramen lacerum. These connect the extracranial pterygoid plexus with the intracranial cavernous sinus and present an unopposed route for infection(Standring, 2008).

The foramen lacerum has been described as a portal of entry into the cranium for tumours, including nasopharyngeal

carcinoma, juvenile angiofibroma, adenoid cystic carcinoma, malignant melanoma, and lymphoma (Christodouleas et al., 2010). 
SOHAG MEDICAL JOURNALA

Vol. 23 No.1 Jan 2019

Material and methods

The present study was undertaken on 100 dry, adult human skulls randomly selected obtained from Anatomy department of medical College of Qena ,Sohag, Assiut and El-Minia university.

a.Morphological study:

The observations were measured on both Right \& Left sides in each skull measured.The antero-posterior and transverse diameter of the foramen were measured (Kumar, 2015). The average, largest, and smallest sizes of the different foramina were listed.

All these data were measured using a digital verniercalliper with an accurate
Morphologic And Morphometric Study

Abeer Fareed Abd EL Naeem

\section{Results}

On the right side:Anteroposterior(AP) diameter varied between smallest and largest diameters: 4.32-16.33 mm. Transverse diameter varied between3.21-19.04mm.

On the left side: AP diameter varied from $4.69-16.48 \mathrm{~mm}$ with mean. Transverse diameter varied from $2.97-17.79 \mathrm{~mm}$ with mean. The mean AP. and T. diameter were shown in table 1 and chart 1.

\begin{tabular}{|l|l|l|}
\hline & AP. diameter & $\begin{array}{l}\text { Transverse. } \\
\text { diameter }\end{array}$ \\
\hline Right side & $10.89 \pm 2.839 \mathrm{~mm}$ & $6.85 \pm 3.15 \mathrm{~mm}$ \\
\hline Left side & $10.88 \pm 2.96 \mathrm{~mm}$ & $6.59 \pm 3.16 \mathrm{~mm}$ \\
\hline
\end{tabular}

Table 1.Mean AP and T. diameter of foramen lacerum in $\mathbf{1 0 0}$ adult skulls.

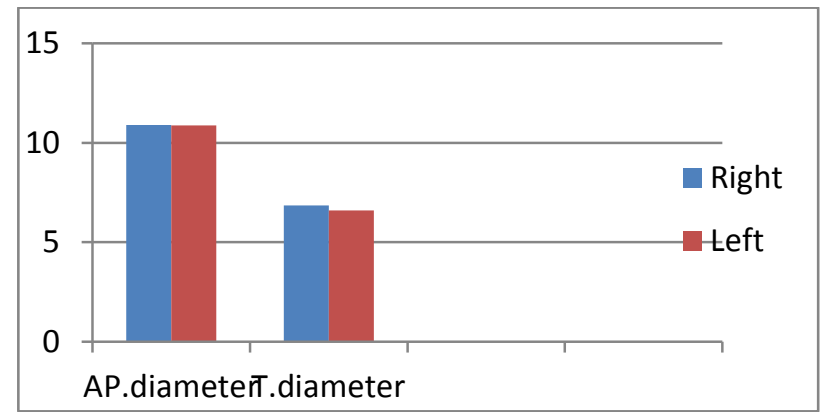

Chart.1. Mean AP and T. diameters of foramen lacerumin 100 adult skulls.

\section{Discussion}

The internal carotid artery passes from the carotid canal in the base of the skull, emerging and coursing superior to foramen lacerum as it exits the carotid canal. The internal carotid artery does not travel through foramen lacerum. The segment of the internal carotid artery that travels above foramenlacerum is called the lacerum segment (Tauber et al., 1999).

The foramen lacerum has been described as a portal of entry 
SOHAG MEDICAL JOURNALA

Vol. 23 No.1 Jan 2019 intothe cranium for

tumours, including nasopharyngeal

carcinoma, juvenile angiofibroma, adenoid cystic carcinoma, malignant melanoma, and lymphoma(Christodouleas,et al.,2010).

The first recorded mention of the foramen lacerum was by anatomist Wenzel Gruber in (Gruber and Wenzel ,1869) Study of the foramen has been neglected for many years because of the small role it plays in intracranial surgery (Tauber et al., 1999).

\section{References}

1. Christodouleas, Hristov , B., Lin, S.H and John P. (2010): Radiation oncology: a question-based review. Philadelphia, Pa.: Lippincott Williams \& Wilkins. p. 138. ISBN 160831444

2. Drake, R.L., Vogl, A.W. and Mitchell, A. W. (2015): Gray s atlas of anatomy. Elsevier/student consult $3^{\text {rd }}$ ed. ch.8 head and neck: 863-940.

3. Gruber and Wenzel (1869):BeitrageZurAnatomie Des Schadelgrundes .ISBN
4. Kumar, A., Ritu and Akhtar, J., (2015): Variations in jugular foramen of human skull. Asian J of Med Sci, 6 (2): 95-98.

5. Lang J. (2001): Skull Base and Related Structures. Schattauer GmbH. ISBN :3794519477.

6. Sangari,S.K., Dossous, P.M. Heineman, $T$. and Mtui, E.P.(2015):Dimensions and Anatomical Variants of the Foramen Transversarium of Typical Cervical Vertebrae.Anatomy Research International

7. Sethi, M., Vasudeva, N. and Mishra, S.(2014): Study of foramen transversaria of first cervical vertebrae and its variations. OA Anatomy, 17;2 (3):25.

8. Snell,(2012): Clincal anatomy by regions.Ch.11 Head and neck: 527. Ch.12 Back :682.

9. Standring, S. (2008): Gray's anatomy 40th Edition. Anatomical Basis Of Clinical Practice, Churchill Livingstone, London, 40:415.

10.Tauber, M; van Loveren, H.R.; Jallo, G.; Romano, A. and Keller, JT (February 1999): "The enigmatic foramen

lacerum". Neurosurgery. 44 (2): 386 91; discussion 391-3. 